\title{
Molecular Analysis of the GNAS1 Gene for the Correct Diagnosis of Albright Hereditary Osteodystrophy and Pseudohypoparathyroidism
}

\author{
LUISA DE SANCTIS, DAMIANO ROMAGNOLO, MARTINA OLIVERO, FABIO BUZI, \\ MOHAMAD MAGHNIE, GIUSEPPE SCIRÈ, ANTONINO CRINÒ, GIAMPIERO IGLI BARONCELLI, \\ MARIACAROLINA SALERNO, SALVATORE DI MAIO, MARCO CAPPA, SALVATORE GROSSO, \\ FRANCO RIGON, ROBERTO LALA, CARLO DE SANCTIS, AND IRMA DIANZANI \\ Department of Pediatric Sciences [L.d.S.], Division of Pediatric Endocrinology [D.R., R.L., C.d.S.], \\ Genetic Cancer Laboratory, I.R.C.C.[M.O.], University of Torino, Torino, Italy; Department of Pediatrics, \\ University of Brescia, Brescia, Italy [F.B.]; Department of Pediatric Sciences, University of Pavia, Pavia, \\ Italy [M.M.]; Department of Pediatrics, University Tor Vergata, Roma, Italy [G.S.]; Endocrine \\ Autoimmune Disease Unit, Ospedale Bambin Gesù, Roma, Italy [A.C.]; Endocrine Unit, Division of \\ Pediatrics, University of Pisa, Pisa, Italy [G.I.B.]; Department of Pediatrics, "Federico II" University, \\ Naples, Italy [M.S.]; Auxo-Endocrine Unit, Santobono-Pausillipon Hospital, Naples, Italy [S.d.M.]; \\ Auxology Unit, Bambino Gesù Children Hospital, Palidoro, Roma, Italy [M.C.]; Department of Pediatrics, \\ University of Siena, Siena, Italy [S.G.]; Department of Pediatrics, University of Padova, Padova, Italy \\ [F.R.]; Department of Medical Sciences, Eastern Piedmont University, Italy [I.D.]
}

\begin{abstract}
ABST
Pseudohypoparathyroidism (PHP) is a heterogeneous disease
characterized by PTH resistance and classified as types Ia, Ib, Ic,
and II, according to its different pathogenesis and phenotype.
PHP-Ia patients show $\mathrm{G}_{\mathrm{s} \alpha}$ protein deficiency, PTH resistance,
and typical Albright hereditary osteodystrophy (AHO). Het-
erozygous mutations in the GNAS1 gene encoding the $\mathrm{G}_{\mathrm{s} \alpha}$
protein have been identified both in PHP-Ia and in pseudop-
seudohypoparathyroidism (PPHP), a disorder with isolated
AHO. A single GNAS1 mutation may be responsible for both
PHP-Ia and PPHP in the same family when inherited from the
maternal and the paternal allele, respectively, suggesting that
GNAS1 is an imprinted gene. To evaluate whether molecular
diagnosis is a useful tool to characterize AHO and PHP when
testing for $\mathrm{G}_{\mathrm{s} \alpha}$ activity and PTH resistance is not available, we
have performed GNAS1 mutational analysis in 43 patients with
PTH resistance and/or AHO. Sequencing of the whole coding
\end{abstract}
PHP (OMIM 103580) was the first human disease to be ascribed to deficient responsiveness to a hormone by otherwise normal target organs (1). It consists of a heterogeneous group of endocrine disorders, whose common feature is resistance to PTH, as shown by hypocalcemia, hyperphosphatemia, and elevation of serum PTH despite normal renal function (2). PTH stimulates the formation of intracellular cAMP by adenylyl

Received August 27, 2001; accepted May 17, 2002.

Correspondence: Luisa de Sanctis, M.D., Ph.D., Department of Pediatric Sciences, 94, Piazza Polonia, 10126 Torino, Italy; e-mail: ldesanct@pediatria.unito.it

DOI: 10.1203/01.PDR.0000059752.07086.A2 region of the GNAS1 gene identified 11 mutations in 18 PHP patients, eight of which have not been reported previously. Inheritance was ascertained in 13 cases, all of whom had PHP-Ia: the mutated alleles were inherited from the mothers, who had AHO (PPHP), consistent with the proposed imprinting mechanism. GNAS1 molecular analysis confirmed the diagnosis of PHP-Ia and PPHP in the mutated patients. Our results stress the usefulness of this approach to obtain a complete diagnosis, expand the GNAS1 mutation spectrum, and illustrate the wide mutation heterogeneity of PHP and PHP-Ia. (Pediatr Res 53: 749-755, 2003)

Abbreviations
PHP, pseudohypoparathyroidism
PPHP, pseudopseudohypoparathyroidism
AHO, Albright hereditary osteodystrophy

cyclase through the activation of $\mathrm{G}_{\mathrm{s}}$ protein $(3,4) . \mathrm{G}_{\mathrm{s}}$ protein belongs to the superfamily of heterotrimeric $\mathrm{G}$ proteins formed of three subunits $(\alpha, \beta, \gamma)$ encoded by separate genes (5). They mediate signal transduction across cell membranes by coupling extracellular receptors to intracellular effector proteins. The activity of hormone-sensitive adenylate cyclase is regulated by at least two $\mathrm{G}$ proteins, one stimulatory $\left(\mathrm{G}_{\mathrm{s}}\right)$ and one inhibitory $\left(\mathrm{G}_{\mathrm{i}}\right)$. G protein specificity is defined by its specific $\alpha$-subunit. $\mathrm{G}_{\mathrm{s} \alpha}$, which binds GTP and stimulates adenylyl cyclase, has GTPase activity and couples multiple receptors to the stimulation of adenylyl cyclase, including those for PTH, TSH, and LH/FSH. 
PHP is divided into two types, I and II, on the basis of differences in the response of cAMP to PTH. In type I patients, renal cAMP production after stimulus is markedly reduced. Type II patients show a normal cAMP urinary response, but a deficient phosphaturic response to $\mathrm{PTH}$, which indicates a defect distal to cAMP generation $(4,6)$. Three subtypes (types Ia, Ib, and Ic) are distinguished clinically and biochemically $(7,8)$. PHP-Ia patients have a deficient $\mathrm{G}_{\mathrm{s} \alpha}$ protein activity, resistance to PTH and often to other hormones (i.e. TSH and gonadotropins), and several distinct physical features, including brachydactyly (i.e. variable shortening of the metacarpals, metatarsals, and phalanges), short stature, obesity, round face, subcutaneous ossifications, and mental retardation, a physical phenotype known as AHO. PHP-Ic patients display multiple hormonal resistance and AHO, but no evidence of $\mathrm{G}_{\mathrm{s} \alpha}$ deficiency, whereas PHP-Ib patients have PTH resistance only.

An approximately $50 \%$ reduction in red cell $\mathrm{G}_{\mathrm{s} \alpha}$ protein bioactivity has been demonstrated in both PHP-Ia subjects (9) and AHO patients without hormone resistance, a condition called PPHP (10). $\mathrm{G}_{\mathrm{s} \alpha}$ is encoded by 13 exons of the GNAS1 gene, located on chromosome 20q13.1 $(11,12)$.

Many PHP-Ia and PPHP patients show heterozygous lossof-function GNAS1 mutations $(13,14)$. Segregation of both phenotypes within the same family is evidence of the variable expressivity of the same mutation (15-17).

This phenotypical variability suggests that other genetic factors influence endocrine function. Genomic imprinting has been postulated, because in PHP/PPHP families with two or more generations PHP-Ia is usually observed with maternal and PPHP with paternal transmission (18-21). Genomic imprinting is an epigenetic phenomenon characterized by preferential expression from a single parental allele. Tissue-specific paternal imprinting has been proposed as an explanation for the parent of origin effect in AHO. If $\mathrm{G}_{\mathrm{s} \alpha}$ is only expressed from the maternal allele in PTH target tissues, e.g. renal proximal tubules, mutations in the maternal allele will disrupt hormone signaling, whereas mutations in the paternal allele will not. Biallelic GNAS1 expression has been demonstrated in other tissues, including lymphocytes, erythrocytes, and fetal tissues. A $50 \%$ reduction of $\mathrm{G}_{\mathrm{s} \alpha}$ activity resulting from a mutation in either allele in these nonimprinted tissues is proposed to result in the AHO phenotype. A paternal imprinting has been demonstrated in the Gnas1 gene in mice (22), and recently in human normal pituitary glands (23).

Linkage studies of PHP-Ib have recently raised additional questions about the imprinting of the 20q13.3 chromosomal region. PHP-Ib families show linkage to $20 \mathrm{q} 13.3$, but no mutation within GNAS1 (24). The paternal-specific imprinting pattern shown for an alternative GNAS1 promoter on both alleles in PHP-Ib patients probably leads to decreased $\mathrm{G}_{\mathrm{s} \alpha}$ expression in renal proximal tubules (25). Finally, other loci have been associated with AHO-like syndromes $(26,27)$.

We report here GNAS1 mutational analysis in 43 Italian subjects from 40 families with PTH resistance, a partial or complete AHO phenotype, or both.

\section{METHODS}

Subjects. Forty-three patients aged 6-24 y from 40 unrelated Italian families (subjects 7 and 8 are twins and subjects 11 and 12, and 13 and 14 are siblings) with PTH resistance, a complete or partial AHO phenotype, or both, followed in several Italian endocrinology clinical units, were included. Calcium-phosphorus metabolism and serum PTH, TSH, FSH, and $\mathrm{LH}$ values were evaluated. The diagnostic criteria for AHO were brachydactyly (brachymetacarpals, metatarsals, or both), short stature, obesity, round face, subcutaneous ossifications, and mental retardation (Tables 1 and 2). Neither $G_{s \alpha}$ activity determination nor the PTH infusion test were performed, because $\mathrm{G}_{\mathrm{s} \alpha}$ activity is not routinely available in a service setting and PTH testing is impeded by the lack of a commercially available PTH. PHP typing was thus incomplete and prompted us to sequence GNAS1 in the whole panel of patients.

Thirteen subjects have an isolated AHO phenotype (cases 31-43), whereas the remaining 30 have biochemical/hormonal findings of hypocalcemia, hyperphosphatemia, and elevation of serum PTH despite normal renal function. This picture is characteristic of PHP. Six of these have isolated PTH resistance (cases 25-30), 24 (from 21 families) have PTH and TSH resistance and an AHO phenotype (cases 1-24). Two subjects with multihormone resistance (cases 8 and 13) showed gonadotropin resistance at pubertal age in addition to PTH and TSH resistance. The clinical/biochemical findings are summarized in Tables 1 and 2. The same clinical and biochemical investigations were performed in both parents, when available.

Informed consent was obtained from all patients or their families. The study has been approved by the applicable institutional review board.

Molecular analysis. Genomic DNA was isolated from peripheral blood leukocytes with the phenol/chloroform method in all patients and their available parents. The 13 exons of the GNAS1 gene were amplified from one patient for each family, using 13 pairs of previously described GNAS1-specific primers $(7,16)$. Amplification of exons $2-12$ included each bordering intron region, whereas a DNA fragment from 20 bp downstream of the initiation codon to the donor site of intron 1 was amplified for exon 1 because of abundance of guanine and cytosine in the bordering regions (7).

The amplification reaction was performed with $500 \mathrm{ng}$ of genomic DNA included in a $50-\mu \mathrm{L}$ PCR mixture containing 50 pmol for each primer, $1 \mathrm{mmol}$ of each dNTP (deoxynucleotidetriphosphate), $1.5 \mathrm{mM}$ magnesium chloride, $50 \mathrm{mM}$ potassium chloride, $10 \mathrm{mM}$ Tris- $\mathrm{HCl}(\mathrm{pH} 8.3), 0.01 \%$ gelatin, and 2 UI Taq DNA polymerase (PerkinElmer Cetus, Branchburg, New Jersey, U.S.A.). After an initial denaturation at $94^{\circ} \mathrm{C}$ for $5 \mathrm{~min}, 35$ cycles of PCR amplification were performed. Each cycle consisted of $60 \mathrm{~s}$ at $94^{\circ} \mathrm{C}$ for denaturation, $60 \mathrm{~s}$ at an annealing temperature ranging from $55-68^{\circ} \mathrm{C}$ depending upon the specific primer pair used, and $120 \mathrm{~s}$ at $72^{\circ} \mathrm{C}$ for DNA extension. The PCR product length was analyzed on $3 \%$ agarose gels, stained with ethidium bromide and visualized with UV light. Gel-purified fragments obtained using the QIAquick Gel Extraction Kit (QIAGEN, Valencia, CA, U.S.A.) were directly sequenced with a semiautomated detection sys- 
Table 1. Clinical, biochemical, and molecular data in 18 patients with GNASI mutations and their relatives

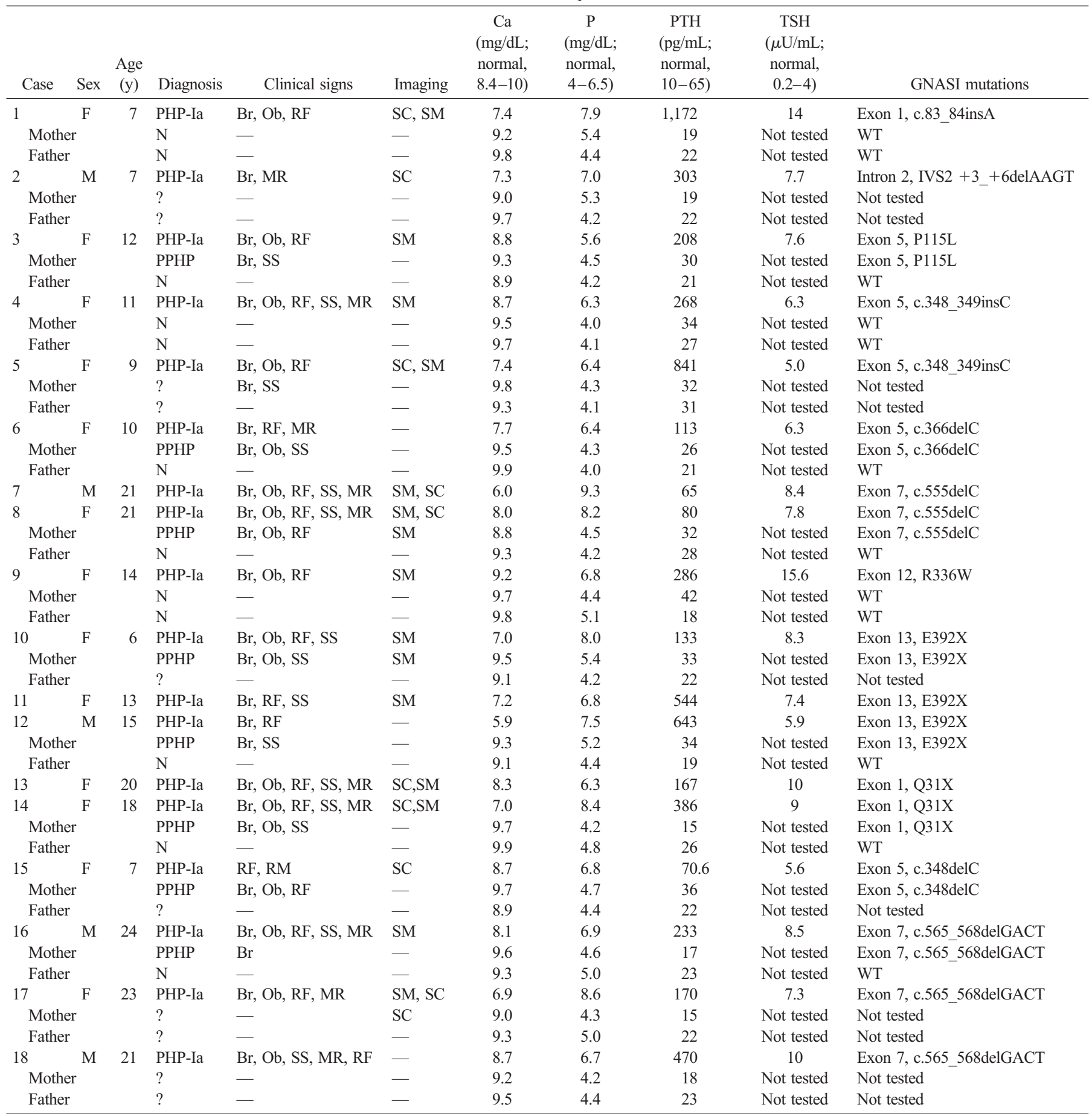

Arabic numbers indicate each proband studied. Ages refer to the present. -, no alteration; F, female; M, male; WT, wild type; N, normal; Br, brachydactyly; Ob, obesity; SC, subcutaneous calcification; RF, round face; SS, short stature $(<2 \mathrm{SD})$; MR, mental retardation; SM, short metacarpals.

tem (ABI 373A sequencer, Applied Biosystems, Foster City, CA, U.S.A.). DNA sequence abnormalities were confirmed by restriction analysis of genomic PCR products using the appropriate endonucleases. The same technique was used to trace segregation of the mutation in each family and test 50-55 unrelated normal individuals.

In a mutated patient (patient 2), total RNA was isolated from peripheral blood leukocytes using the QIAamp RNA blood Mini kit (QIAGEN). Reverse transcription (RT)-PCR was performed on $1 \mu \mathrm{g}$ total RNA using a protocol described elsewhere (28). The PCR cycling profile consisted of an initial 7-min denaturation at $95^{\circ} \mathrm{C}$, followed by 35 cycles of denaturation $\left(95^{\circ} \mathrm{C}, 30 \mathrm{~s}\right)$, annealing $\left(65^{\circ} \mathrm{C}, 45 \mathrm{~s}\right)$, and extension $\left(72^{\circ} \mathrm{C}, 45 \mathrm{~s}\right)$, with a final cycle with a 7 -min extension. The following upstream and downstream PCR primers, encompassing a region spanning exon 1 to exon 4, were used: 5'CAGAAGGACAAGCAGGTCTAC-3' and 5'-TTCCGTTGGTTTCACGTCCTG-3'. RT-PCR reactions without added reverse transcriptase were performed in parallel to rule out DNA contamination. RT-PCR reactions were run on $3 \%$ low 
Table 2. Clinical, biochemical, and molecular data in the 25 patients without GNASI mutations

\begin{tabular}{|c|c|c|c|c|c|c|c|c|c|c|}
\hline Case & Sex & $\begin{array}{c}\text { Age } \\
\text { (y) }\end{array}$ & Diagnosis & Clinical signs & Imaging & $\begin{array}{c}\mathrm{Ca} \\
(\mathrm{mg} / \mathrm{dL} ; \\
\text { normal, } \\
8.4-10)\end{array}$ & $\begin{array}{c}\mathrm{P} \\
\text { (mg/dL; } \\
\text { normal, } \\
4-6.5 \text { ) }\end{array}$ & $\begin{array}{c}\text { PTH } \\
\text { (pg/mL; } \\
\text { normal, } \\
10-65 \text { ) }\end{array}$ & $\begin{array}{c}\mathrm{TSH} \\
(\mu \mathrm{U} / \mathrm{mL} ; \\
\text { normal, } \\
0.2-4)\end{array}$ & $\begin{array}{l}\text { Clinical signs } \\
\text { in the family }\end{array}$ \\
\hline 20 & $\mathrm{~F}$ & 4 & PHP-Ia or Ic? & $\mathrm{Br}, \mathrm{Ob}, \mathrm{RF}, \mathrm{SS}$ & $\mathrm{SM}, \mathrm{SC}$ & 8.5 & 6.6 & 281 & 8.8 & Mother: $\mathrm{Br}$ \\
\hline 21 & M & 24 & PHP-Ia or Ic? & $\mathrm{Br}, \mathrm{Ob}, \mathrm{RF}, \mathrm{MR}$ & $\mathrm{SM}, \mathrm{SC}$ & 7.0 & 8.5 & 130 & 10 & Mother: $\mathrm{Br}, \mathrm{Ob}, \mathrm{RF}$ \\
\hline 22 & M & 26 & PHP-Ia or Ic? & $\mathrm{Br}, \mathrm{Ob}, \mathrm{RF}, \mathrm{SS}, \mathrm{MR}$ & SM & 8.7 & 4.6 & 94 & 9 & Mother: $\mathrm{Br}, \mathrm{Ob}, \mathrm{RF}$ \\
\hline 25 & $\mathrm{M}$ & 18 & PHP-Ib? & - & - & 9.4 & 5.5 & 203 & 3.6 & - \\
\hline 26 & F & 19 & PHP-Ib? & - & - & 7.8 & 5.9 & 188 & 3.6 & - \\
\hline 27 & $\mathrm{M}$ & 21 & PHP-Ib? & - & - & 6.6 & 7.6 & 90 & 3.7 & - \\
\hline 28 & $\mathrm{~F}$ & 13 & PHP-Ib? & - & - & 9.6 & 8.5 & 615 & 1.8 & - \\
\hline 29 & $\mathrm{~F}$ & 17 & PHP-Ib? & - & - & 5.1 & 4.4 & 394 & 0.8 & - \\
\hline 30 & $\mathrm{~F}$ & 14 & PHP-Ib? & - & - & 4.7 & 9.1 & 331 & 4.9 & - \\
\hline 35 & $\mathrm{~F}$ & 13 & $\mathrm{AHO} ?$ & $\mathrm{Br}, \mathrm{Ob}, \mathrm{RF}, \mathrm{SS}$ & SM & 9.2 & 2.9 & 58 & 3.3 & - \\
\hline 36 & $\mathrm{~F}$ & 12 & $\mathrm{AHO} ?$ & $\mathrm{Br}, \mathrm{Ob}, \mathrm{RF}, \mathrm{SS}$ & $\mathrm{SM}, \mathrm{SC}$ & 9.2 & 5 & 19 & 2.6 & - \\
\hline 37 & $\mathrm{~F}$ & 14 & $\mathrm{AHO} ?$ & $\mathrm{BR}, \mathrm{Ob}$ & - & 9.8 & 4.8 & 20 & 2.8 & - \\
\hline 38 & $\mathrm{~F}$ & 16 & $\mathrm{AHO} ?$ & $\mathrm{Br}, \mathrm{Ob}$ & SM & 9.6 & 4.4 & 43 & 1.1 & - \\
\hline 39 & $\mathrm{~F}$ & 11 & $\mathrm{AHO} ?$ & - & - & 9.8 & 3.2 & 26 & 1.4 & - \\
\hline 40 & $\mathrm{~F}$ & 14 & $\mathrm{AHO} ?$ & $\mathrm{Br}$ & SM & 9.8 & 3.8 & 26 & 1.4 & - \\
\hline 41 & $\mathrm{~F}$ & 15 & $\mathrm{AHO} ?$ & $\mathrm{Br}, \mathrm{SS}$ & SM & 9.0 & 4.2 & 19 & 1.6 & - \\
\hline 42 & $\mathrm{~F}$ & 13 & $\mathrm{AHO} ?$ & $\mathrm{Br}, \mathrm{RF}, \mathrm{SS}$ & SM & 9.0 & 5.9 & 55 & 3.3 & - \\
\hline 43 & $\mathrm{~F}$ & 12 & $\mathrm{AHO} ?$ & $\mathrm{SS}, \mathrm{MR}, \mathrm{Ob}, \mathrm{RF}$ & SM & 9.4 & 5.3 & 16.5 & 2.2 & - \\
\hline
\end{tabular}

Arabic numbers indicate each proband studied. Ages refer to the present. —, no alteration; F, female; M, male; WT, wild type; N, normal; Br, brachydactyly; $\mathrm{Ob}$, obesity; SC, subcutaneous calcification; RF, round face; SS, short stature ( $<2 \mathrm{SD})$; MR, mental retardation; SM, short metacarpals.

melt agarose gel. Specific products were excised, purified using the QIAquick Kit (QIAGEN), and directly sequenced with a semiautomated detection system (ABI 373A sequencer, Applied Biosystems).

\section{RESULTS}

Eleven mutations were identified in 18 patients: c.83_84insA, IVS2 +3_+6delAAGT, P115L, c.348_349insC, c.366 delC, c.555delC, R336W, E392X, Q31X, c.348delC, and c.565_568delGACT.

The first eight mutations are novel. Q31X and c.348delC are previously described mutations (14, 29). The c.565_568delGACT mutation has been reported in several AHO patients from different populations.
The c.83_84insA mutation is a single base (A) insertion at codon 28 in exon 1 (Table 3). It was identified in a patient (case 1 ), who was heterozygous and showed multihormone resistance and four AHO signs (Table 1). The mutation causes a frameshift with the creation of a premature stop codon (TGA) in exon 2 after 30 codons. It was absent in both parents, who are free from AHO signs and hormonal resistance, and is presumably a de novo mutation (Table 1 ).

IVS2 +3_+6delAAGT is a 4 bp deletion beginning at the third base of intron 2 donor splice site (Table 3 ). It disrupts the highly conserved 5' splice site consensus sequence (30). Analysis with a splice site prediction program (Splice Site Prediction by Neural Network, available at www.fruitfly.org/ seq_tools/splice.html) predicts the activation of a cryptic splice

Table 3. GNASI mutations detected in 18 patients with multihormone resistance and AHO

\begin{tabular}{|c|c|c|c|c|}
\hline Case & Gene position & Codon & Base change & $\begin{array}{c}\text { Restriction enzyme } \\
\text { (recognition site) }\end{array}$ \\
\hline 1 & Exon 1 & 28 & c.83_84insA & - \\
\hline 2 & Intron 2 & - & IVS $\overline{2}+3+6 \operatorname{delAAGT}$ & - \\
\hline 3 & Exon 5 & 115 & c. $344 \mathrm{C}>\overline{\mathrm{T}}(\mathrm{P} 115 \mathrm{~L})$ & BanI (G/GpyPuCC) \\
\hline 4,5 & Exon 5 & $115-116$ & c. $348-349 \mathrm{insC}$ & - \\
\hline 6 & Exon 5 & $121-122$ & c.366delC & - \\
\hline 7,8 & Exon 7 & 185 & c.555delC & Sau3AI (/GATC) \\
\hline 9 & Exon 12 & 336 & c. $1006 \mathrm{C}>\mathrm{T}(\mathrm{R} 336 \mathrm{~W})$ & HpaII (C/CGG) \\
\hline $10-12$ & Exon 13 & 392 & c.1174G > T (E392X) & ScaI (AGT/ACT) \\
\hline 13,14 & Exon 1 & 31 & Q31X & - \\
\hline 15 & Exon 5 & $115-116$ & c.348delC & - \\
\hline $16-18$ & Exon 7 & $188-189$ & c.565_568delGACT & - \\
\hline
\end{tabular}


site beginning at base 33 of intron 2, resulting in the addition of nine amino acids encoded by the intronic translated sequence after glutamic acid 71. A frameshift is then expected and a premature termination is encountered in the first three bases in exon 4 (TGA). RT-PCR reaction encompassing the exon 1 to exon 4 region resulted in multiple products. Four primary transcripts are normally derived from GNAS1 and result from the combined effects of two alternative splicing events. The full-length transcript produces a $52-\mathrm{kD}$ protein (isoform 1 and 2), whereas an alternative splicing of exon 3 gives rise to a shortened $45-\mathrm{kD}$ isoform (isoforms 3 and 4 ). The use of an alternative splice acceptor site for exon 4, $3 \mathrm{bp}$ upstream, results in insertion of a serine residue in isoforms 2 and 4 (14). RT-PCR from patient 2 resulted in products of correct size for these normal fragments $(147,150,192$, and 195 bp) and in abnormal products $(175,178,220$, and $223 \mathrm{bp})$ corresponding to the $28 \mathrm{bp}$ addition that results from the use of the cryptic splice site. Sequencing of abnormal products confirmed the use of this cryptic splice site (data not shown). Thus, this mutation is expected to dramatically disrupt the protein structure and function. The patient was heterozygous for this mutation and showed PTH resistance and three AHO signs (case 2) (Table 1). This mutation was absent in 50 control subjects, who showed normal sequences at this site.

P115L (c.344C $>$ T) was identified in a heterozygous patient with multihormonal resistance and three AHO signs (case 3) (Table 1). It causes the substitution of the normally encoded proline with leucine. The mutation was confirmed by a restriction analysis with the specific endonuclease BamI (New England Biolabs, Beverly, MA, U.S.A.) that recognizes the sequence G/GpyPuCC (Table 3). The same technique was used to rule out the mutation in 55 control subjects. The mutation was also identified in the mother, who showed brachydactyly and short stature without any hormonal derangement (Table 1).

The c.348_349insC mutation is a single base (C) insertion at codons 115 and 116 in exon 5 (Table 3), represented by two triplets of Cs, that encode for two prolines. It was identified in two patients (cases 4 and 5), who were heterozygous and showed multihormone resistance and five and four AHO signs, respectively (Table 1). The mutation causes a frameshift, with the creation of a premature stop codon after 22 codons. This mutation was searched for and excluded in 50 control subjects, who showed normal sequences at this site. It was absent in both parents of patient 4, who are free from AHO signs and hormonal resistance, and thus is a de novo mutation (Table 1).

The c.366delC mutation is a single base (C) deletion in the third base of codon 121, represented by the triplet AAC or in a base of codon 122, represented by the triplet CCC in exon 5 (Table 3). It was identified in a patient (case 6), who was heterozygous and showed multihormone resistance and three AHO signs (Table 1). The mutation causes a frameshift with the creation of a premature stop codon after 9 or 10 codons. This mutation was inherited from the mother, who shows brachydactyly, obesity, and short stature without any hormonal resistance (Table 1).

The c.555delC mutation is a single base (C) deletion in the third base of codon 185 in exon 7 (Table 3). It was identified in twins (cases 7 and 8), who were heterozygous and showed multihormone resistance and a complete AHO phenotype (Table 1). The mutation causes a frameshift, with the creation of a premature stop codon after 20 codons. It was confirmed by restriction analysis with the specific endonuclease Sau3AI (New England Biolabs) that recognizes and cuts the sequence/ GATC (Table 3). The same technique was used to rule out the mutation in 55 control subjects. This mutation was inherited from the mother, who shows brachydactyly, obesity, and round face, without any hormonal resistance (Table 1).

$\mathrm{R} 336 \mathrm{~W}$ is a missense mutation (c. $1006 \mathrm{C}>\mathrm{T}$ ) at codon 336 in exon 12. It was identified in a heterozygous patient (case 9) with multihormone resistance and three AHO signs (Table 1). R336W causes the substitution of the normally encoded arginine with tryptophan. The mutation was confirmed by restriction analysis with the specific endonuclease HpaII (New England Biolabs) that recognizes the sequence C/CGG (Table 3). The same technique was used to rule out the mutation in 55 control subjects. Because R336W is absent in both parents, who do not show any AHO sign nor any hormonal resistance, it is likely to be a de novo mutation.

E392X is a nonsense mutation (c.1174G $>$ T) at codon 392 in exon 13; the aspartic acid normally encoded at this codon is replaced by a stop codon to yield a truncated protein (Table 3). The mutation was identified in three heterozygous patients [case 10 and cases 11 and 12 (siblings)] from two unrelated families with multihormone resistance and four, three, and two AHO signs, respectively (Table 1), and confirmed by restriction analysis with the specific endonuclease Scal (New England Biolabs) that recognizes the sequence AGT/ACT (Table $3)$. The same technique was used to rule out the mutation in 50 control subjects. This mutation was inherited from the two mothers, who show AHO signs without any hormonal resistance (Table 1).

Q31X is a previously reported nonsense mutation (14): it is a missense mutation (c.91C $>\mathrm{T}$ ) at codon 31 in exon 1. It was identified in two heterozygous sisters (cases 13 and 14) with multihormone resistance and a complete AHO phenotype and inherited from the mother, who shows brachydactyly, obesity, and short stature, without any hormonal resistance (Table 1).

The c.348delC mutation is a previously described single base (C) deletion at codons 115-116 in exon 5, represented by two triplets of Cs (29) (Table 3). It was identified in a patient (case 15), who was heterozygous and showed multihormone resistance and three AHO signs (Table 1). The mutation causes a frameshift with the creation of a premature stop codon after 15 codons. This mutation was inherited from the mother, who shows brachydactyly, obesity, and round face, without any hormonal resistance (Table 1).

The c.565_568delGACT at codon 189-190 in exon 7 (31, 32) (Table 3) was identified in three heterozygous patients (cases 16-18) with multihormone resistance and an AHO phenotype (Table 1). This mutation results in a frameshift and a premature termination at codon 202; in case 17, it was inherited from the mother, who shows brachydactyly (Table 1). This mutation can be regarded as a common mutation. It has been found in 15 PHP-Ia families, including four of 11 Italian families (three reported here, one in a previous 
paper) (33) in whom GNAS1 mutations have been identified to date.

\section{DISCUSSION}

Recent findings have partially elucidated the phenotypes associated with PTH resistance, but many aspects are still obscure. Different diseases are associated with mutations in GNAS1: somatic activating mutations occur in several endocrine tumors and in McCune-Albright syndrome (a condition characterized by polyostotic fibrous dysplasia and endocrine dysfunction, such as hyperthyroidism and precocious puberty); AHO is caused by germline loss-of-function mutations. One mutation (A366S) is associated with both activating and inactivating phenotypic features: it leads to constitutive activation of adenylyl cyclase, but is thermolabile at $37^{\circ} \mathrm{C}$. Thus, its effect is only apparent in the testis and results in testitoxicosis, but with PTH resistance and an AHO phenotype.

Sixty-three mutations leading to PHP-Ia and PPHP have been reported. Most are private, and only the deletion in exon 7 can be considered a common mutation. It often arises as a de novo event (14).

This article reports the molecular analysis of the entire coding sequences of the GNAS1 gene in 43 Italian patients with PHP and/or AHO from 40 unrelated families. Thirteen patients had an isolated AHO phenotype, whereas 30 subjects (from 27 families) had biochemical/hormonal findings of hypocalcemia, hyperphosphatemia, and elevation of serum PTH despite normal renal function. This picture is characteristic of PHP. Eight new mutations, a common deletion of $4 \mathrm{bp}$ in exon 7 , and two previously reported mutations have been identified in 18 subjects from 15 families.

In 15 of 27 PHP patients, GNAS1 analysis confirmed the diagnosis of PHP-Ia, in the absence of PTH and $\mathrm{G}_{\mathrm{s} \alpha}$ activity testing. The abnormal allele for each mutation segregated with the disease in multiplex families; mutant alleles were not found in either unaffected family members or 50-55 normal subjects. These mutations may thus be supposed to be responsible for the disease. IVS2 +3_+6delAAGT disrupts the highly conserved 5' splice site sequence of intron 2 and activates a cryptic splice site located 28 bp downstream intron 2 (30). A truncated protein lacking important domains for adenyl cyclase activation and receptor selectivity is predicted. An amino acid substitution at codon 115 has been described by Ahmed et al. (34): their mutation is different from ours because the proline is replaced by a serine, instead of a leucine. Both nuclear magnetic resonance and crystal structure studies of $G_{s \alpha}$ demonstrate that proline 115 is important for correct protein folding $(34,35)$. Its substitution is predicted to disrupt the highly conserved domain of $\mathrm{G}_{\mathrm{s} \alpha}$ that interacts with adenylate cyclase (36). At codon 115-116 in exon 5 we found another two mutations, a single base insertion (c.348_349insC) and a single base deletion (c.348delC): the presence of six Cs at these codons renders difficult to describe the insertion/deletion of another $\mathrm{C}$ because the exact position of the mutation cannot be determined precisely and suggests that these mutations are the consequence of spontaneous DNA polymerase slippage during replication, as described in other diseases (37). For
c.83_84insA, c.348_349insC, c.348delC, and c.555delC a nonsense-mediated mRNA decay (38) or a truncated $\mathrm{G}_{\mathrm{s} \alpha}$ protein is expected. In the latter case, most of the guanine nucleotidebinding pocket would be missing as well as regions critical for receptor and effector interaction. $\mathrm{R} 336 \mathrm{~W}$ is an Arg to Trp substitution that resides in the $\alpha 4-\beta 6$ loop of $\mathrm{G}_{\mathrm{s} \alpha}$. Substitutions in this region might abolish activation of adenylyl cyclase, because this loop supports the cyclase binding site. Moreover, the $\mathrm{COOH}$-terminus of $\mathrm{G}_{\mathrm{s} \alpha}$ contributes to receptor selectivity, as the $\alpha 4-\beta 6$ loop and the $\alpha 5$ helix form a plane on the back side of $\mathrm{G}_{\mathrm{s} \alpha}$ that may interact with receptors (35). Similarly, the nonsense mutation E392X may cause a nonsense-mediated mRNA decay (38) or produce a truncated protein that lacks a part of the C-terminus that is probably important for receptor selectivity (35). The Q31X mutation has been already reported: it causes a truncated protein that lacks most protein domains (14). The 4-bp deletion in exon 7 is associated with a frameshift at codon 189-190 and premature termination at codon 202. This mutation is known to result in a $50 \%$ reduction in GNAS1, whose mRNA sequencing reveals only wild type consistent with nonsense-mediated decay (38) or a reduction in expression of mRNA from the mutant allele $(31,32)$.

In all characterized kindreds with inherited mutation in our panel, the same mutations were present in the PPHP mothers and in the PHP-Ia patients. This inheritance pattern shows that the mutated PHP-Ia patients harbored the GNAS1 heterozygous change on the maternal allele. Thus, our results point to paternal imprinting for $\mathrm{G}_{\mathrm{s} \alpha}$ in agreement with previous reports (18-22). Paternal imprinting of $\mathrm{G}_{\mathrm{s} \alpha}$ has been confirmed in normal human pituitary glands (23): it refers to silencing of the paternal allele in specific tissues. This mechanism could also be present in other specific tissues, such as renal proximal tubules or thyroid glands, and could explain multihormonal resistance. If $\mathrm{G}_{\mathrm{s} \alpha}$ is only expressed by the maternal allele, its mutations will disrupt hormone signaling, whereas those in the paternal allele will have very little effect.

In this study, GNAS1 mutational analysis has been performed in 40 families with uncharacterized PTH resistance, at least one AHO sign (brachydactyly), or both. We used broad phenotypic criteria to evaluate the usefulness of a molecular approach in the diagnosis of PHP/PPHP. In 21 families (24 affected subjects), the presence of AHO and multihormone resistance suggested PHP-Ia or PHP-Ic. A causal mutation in GNAS1 was found in 15 of these families, i.e. a mutation detection rate of $71.4 \%$, as reported for other series $(14,39)$.

The six molecularly uncharacterized patients (cases 19-24) may harbor GNAS1 mutations in other regions not screened by our approach, such as introns or the promoter. Lastly, they may have PHP-Ic, whose molecular defects have not yet been recognized.

Six subjects with isolated PTH resistance may have PHP-Ib. Analysis of imprinting of the region encompassing exon 1A could show whether this is true. Finally, the 13 patients with isolated AHO without mutations in the GNAS1 coding sequence display a partial AHO phenotype and none have family history of AHO. Their features are either nonspecific (such as obesity or mental retardation) or are also present in other disorders (such as brachydactyly), including Turner's syn- 
drome, acrodysostosis. and the inherited AHO-like syndrome associated with deletions at 2q37 (40, 41). Therefore, these findings alone cannot provide a conclusive diagnosis of PPHP. This, indeed, should only be made in patients with characteristic features of AHO who either are in PHP type-Ia kindreds, or in whom a $\mathrm{G}_{\mathrm{s}}$ defect has been demonstrated by genetic or laboratory testing.

\section{CONCLUSION}

In conclusion, our results further expand the molecular pathophysiology of PHP and underscore its genetic heterogeneity. This study brings to 11 the mutations so far identified in the Italian population. These are private. apart from a common deletion in exon 7, found in 5 of 19 of the PHP-Ia Italian population (33).

Our results stress the usefulness of molecular analysis to confirm a diagnosis of $\mathrm{G}_{\mathrm{s} \alpha}$ deficiency when testing for $\mathrm{G}_{\mathrm{s} \alpha}$ activity and PTH resistance is not feasible. Implementation of rapid methods for wide mutation screening, such as denaturing HPLC (42), will greatly reduce the need for sequencing and may thus be applicable to clinical settings.

\section{REFERENCES}

1. Albright F, Burnett CH, Smith PH 1942 Pseudohypoparathyroidism: an example of 'Seabright-Bantam syndrome'. Endocrinology 30:922-932

2. Kinard RE, Walton JE, Buckwalter JA 1979 Pseudohypoparathyroidism. Arch Intern Med 139:204-207

3. Levine MA, Downs Jr RW, Moses AM 1977 Resistance to multiple hormones in patients with pseudohypoparathyroidism. Association with deficient activity of guanine nucleotide regulatory protein. Am J Med 296:140-144

4. Chase LR, Melson GL, Aurbach GD 1969 Pseudohypoparathyroidism: defective excretion of 3',5'-AMP in response to parathyroid hormone. J Clin Invest 48:18321844

5. Hamm HE, Gilchrist A 1996 Heterotrimeric G proteins. Curr Opin Cell Biol 8:189-196

6. Marguet C, Mallet E, Basuyau JP, Martin D, Leroy M, Brunelle P 1997 Clinical and biological heterogeneity in pseudohypoparathyroidism syndrome. Horm Res 48:120 130

7. Weinstein LS 1998 Albright hereditary osteodystrophy, pseudohypoparathyroidism, and Gs deficiency. In: Spiegel AM (ed) Contemporary Endocrinology: G proteins, Receptors, and Disease. Humana Press, Totawa, NJ, pp 23-56

8. Bastepe M, Juppner H 2000 Pseudohypoparathyroidism: new insight into an old disease Endocrinol Metab Clin North Am 29:569-589

9. Levine MA, Downs Jr RW, Singer M, Marx SJ, Aurbach GD, Spiegel AM 1980 Deficient activity of guanine nucleotide regulatory protein in erythrocytes from patients with pseudohypoparathyroidism. Biochem Biophys Res Commun 94:13191324

10. Levine MA, Jap TS, Mauseth RS, Downs Jr RW, Spiegel AM 1986 Activity of the stimulatory guanine nucleotide-binding regulatory protein in erythrocytes from patients with pseudohypoparathyroidism and pseudopseudohypoparathyroidism: biochemical evidence, endocrine, and genetic analysis of Albright's hereditary osteodystrophy in six kindreds. J Clin Endocrinol Metab 62:497-502

11. Kozasa T, Itoh H, Tsukamoto T, Kaziro Y 1988 Isolation and characterization of the human Gs $\alpha$ gene. Proc Natl Acad Sci U S A 85:2081-2085

12. Levine MA, Ahn TG, Klupt SF, Kaufman KD, Smallwood PM, Bourne HR, Sullivan KA, Van Dop C 1988 Genetic deficiency of the $\alpha$ subunit of the guanine nucleotidebinding protein Gs as the molecular basis for Albright hereditary osteodystrophy. Proc Natl Acad Sci U S A 85:617-621

13. Weinstein LS, Gejman PV, Friedman E, Kadowaki T, Collins RM, Gershon ES, Spiegel AM 1990 Mutations of the Gs $\alpha$-subunit gene in Albright hereditary osteodystrophy detected by denaturing gradient gel electrophoresis. Proc Natl Acad Sci U S A 87:8287-8290

14. Aldred MA, Trembath RC 2000 Activating and inactivating mutations in the human GNAS1 gene. Hum Mutat 16:183-189

15. Patten JL, Johns DR, Valle D, Eil C, Gruppuso PA, Steele G, Smallwood PM, Levine MA 1990 Mutations in the gene encoding the stimulatory G protein of adenylate cyclase in Albright's hereditary osteodystrophy. N Engl J Med 32:1412-1419
16. Miric A, Vechio JD, Levine MA 1993 Heterogeneous mutations in the gene encoding the alpha subunit of the stimulatory G protein of adenylyl cyclase in Albright hereditary osteodystrophy. J Clin Endocrinol Metab 75:171-184

17. Fisher JA, Egert F, Werder E, Born W 1998 An inherited mutation associated with functional deficiency of the $\alpha$-subunit of the guanine nucleotide-binding protein Gs in pseudo- and pseudopseudohypoparathyroidism. J Clin Endocr Metab 83:935-938

18. Davies SJ, Hughes HE 1993 Imprinting in Albright's hereditary osteodistrophy. J Med Genet 30:101-103

19. Campbell R, Gosden CM, Bonthron DT 1994 Parental origin of transcription from the human GNAS1 gene. J Med Genet 31:607-614

20. Wilson LC, Oude Luttikhuis MEM, Clayton PT, Fraser WD, Trembath RC 1994 Parental origin of Gs $\alpha$ gene mutations in Albright's hereditary osteodystrophy. J Med Genet 31:835-839

21. Williams AJ, Wilkinson JL, Taylor WH 1997 Pseudohypoparathyroidism: variable manifestations within a family. Arch Dis Child 52:798-799

22. Yu S, Yu D, Lee E, Eckhaus M, Lee R, Corria Z, Accili D, Westphal H, Weinstein LS 1998 Variable and tissue-specific hormone resistance in heterotrimeric G protein $\alpha$-subunit (Gs $\alpha$ ) knockout mice is due to tissue-specific imprinting of the Gs $\alpha$ gene. Proc Natl Acad Sci U S A 95:8715-8720

23. Hayward BE, Barlier A, Korbonits M, Grossman AB, Jacquet P, Enjalbert A, Bonthron DT 2001 Imprinting of the $\mathrm{g}(\mathrm{s})$ alpha gene GNAS1 in the pathogenesis of acromegaly. J Clin Invest 107:31-36

24. Juppner H, Schipani E, Bastepe M, Cole DEC, Lawson ML, Mannstadt M, Hendy GN, Plotkin H, Koshiyama H, Koh T, Crawford JD, Olsen BR, Vikkula M 1998 The gene responsible for pseudohypoparathyroidism type $\mathrm{Ib}$ is paternally imprinted and maps in four unrelated kindreds to chromosome 20q13.3. Proc Natl Acad Sci U S A 95:11798-11803

25. Liu J, Litman D, Rosenberg MJ, Yu S, Biesecker LG, Weinstein LS 2000 A GNAS1 imprinting defect in pseudohypoparathyroidism type Ib. J Clin Invest 106:1167-1174

26. Hedeland H, Bentorp K, Arheden K, Kristoffersson U 1992 Pseudohypoparathyroidism type I and Albright's hereditary osteodystrophy with a proximal $15 \mathrm{q}$ chromosomal deletion in the mother and daughter. Clin Genet 42:129-134

27. Phelan MC, Rogers RC, Clarkson KB, Bowyer FP, Levine MA, Estabrooks LL, Severson MC, Dobyns WB 1995 Albright's hereditary osteodystrophy and $\operatorname{del}(2)(q 37.3)$ in four unrelated individuals. Am J Med Genet 58:1-7

28. Warner DR, Gejman PV, Collins RM, Weinstein LS 1997 A novel mutation adjacent to the switch III domain of $\mathrm{G}_{\mathrm{s} \alpha}$ in a patient with pseudohypoparathyroidism. Mol Endocrinol 11:1718-1727

29. Shapira H, Mouallem M, Shapiro MS, Weisman Y, Farfel Z 1996 Pseudohypoparathyroidism type Ia: two new heterozygous frameshift mutations in exon 5 and 10 of the Gs alpha gene. Hum Genet 97:73-75

30. Senapathy P, Shapiro MB, Harris NL 1990 Splice junctions, branch point sites and exons: sequence statistics, identification, and application to the genome project. Methods Enzymol 183: 252-278

31. Weinstein LS, Gejman PV, de Mazancourt P, American N, Spiegel AM 1992 A heterozygous 4 bp deletion mutation in the Gs $\alpha$ gene (GNAS1) in a patient with Albright hereditary osteodystrophy. Genomics 13:1319-1321

32. Yu S, Yu D, Hainline BE, Brener JL, Wilson KA, Wilson LC, Luttikhuis MEO, Trembath RC, Weinstein LS 1995 A deletion hot-spot in exon 7 of the Gs $\alpha$ gene (GNAS1) in patients with Albright hereditary osteodystrophy. Hum Mol Genet 4:2001-2002

33. Mantovani G, Romoli R, Weber G, Brunelli V, De Menis E, Beccio S, Beck-Pecoz P, Spada A 2000 Mutational analysis in patients with pseudohypoparathyroidism: identification of two novel mutations. J Clin Endocrinol Metab 85:4243-4248

34. Ahmed SF, Dixon PH, Bonthron DT, Stirling HF, Barr DGD, Kelnar CJH, Thakker RV 1998 GNAS1 Mutational analysis in pseudohypoparathyroidism. Clin Endocrinol 49:525-531

35. Sunahara RK, Tesmer JJG, Gilman AG, Sprang SR 1997 Crystal structure of the adenylyl cyclase activator $\mathrm{G}_{\mathrm{s} \alpha}$. Science $278: 1943-1947$

36. Pennington SR 1994 GTP-binding proteins: heterotrimeric G proteins. CCQ 1:169342

37. Caluseriu O, Lucci Cordisco E, Viel A, Majore S, Nascimbeni R, Pucciarelli S, Genuardi M 2001 Four novel MSH2 and MLH1 frameshift mutations and occurrence of a breast cancer phenocopy in hereditary nonpolyposis colorectal cancer. Hum Mutat 17:521

38. Cheng J, Fogel-Petrovic M, Maquat LE 1990 Translation to near the distal end of the penultimate exon is required for normal levels of spliced triosephosphate isomerase mRNA. Mol Cell Biol 10:5215-5225

39. Ahrens W, Hiort O, Staedt P, Kirschner T, Marschke C, Kruse K 2001 Analysis of GNAS1 gene in Albright's hereditary osteodystrophy. J Clin Endocrinol Metab $86: 4630-4634$

40. Wilson LC, Leverton K, Oude Luttikhuis MEM 1995 Brachydactyly and mental retardation: an Albright hereditary osteodystrophy-like syndrome localized to 2q37. Am J Hum Genet 56:400-407

41. Sakaguchi H, Sanke T, Ohagi S, Iiri T, Nanjo K 1998 A case of Albright's hereditary osteodystrophy-like syndrome complicated by several endocrinopathies: normal Gs $\alpha$ gene and chromosome 2q37. J Clin Endocrinol Metab 83:1563-1565

42. Spiegelman JI, Mindrinos MN, Oefner PJ 2000 High-accuracy DNA sequence variation screening by DHPLC. Biotechniques 29:1084-1090 